\title{
Attitudes that Students Believe Best Characterize Engineers
}

\section{Dr. Angela R Bielefeldt, University of Colorado, Boulder}

Angela Bielefeldt is a professor at the University of Colorado Boulder in the Department of Civil, Environmental, and Architectural Engineering (CEAE). She serves as the ABET assessment coordinator for the department and its three accredited bachelor's degrees. Professor Bielefeldt is the faculty director of the Sustainable By Design Residential Academic Program, a living-learning community where interdisciplinary students learn about and practice sustainability. Professor Bielefeldt's research interests in engineering education include service-learning, sustainable engineering, social responsibility, ethics, and diversity. Bielefeldt is also a licensed P.E.

\section{Greg Rulifson P.E., University of Colorado, Boulder}

Greg Rulifson is a Civil Engineering doctoral candidate focused on qualitative engineering education research while also completing the Engineering in Developing Communities certificate. Greg earned his bachelor's degree in Civil Engineering with a minor in Global Poverty and Practice from UC Berkeley where he acquired a passion for using engineering to facilitate developing communities' capacity for success. He earned his master's degree in Structural Engineering and Risk Analysis from Stanford University. His upcoming dissertation will focus on how student's connections of social responsibility and engineering change throughout college and what are the social responsibility-related reasons some students choose to leave engineering. 


\title{
Attitudes that Students Believe Best Characterize Engineers
}

\begin{abstract}
Beyond knowledge and cognitive learning outcomes, engineering education should achieve affective outcomes. The American Society of Civil Engineers (ASCE) has articulated attitudes that are supportive of the professional practice of engineering. This research explored the extent to which engineering students believed that various attitudes were characteristic of both engineers and themselves. Three groups participated in the study: (1) 120 first year civil, environmental, and architectural engineering students; (2) 18 senior civil engineering students; and (3) 21 students at the end of their junior year of college (in 7 different engineering majors, attending 5 different institutions). Students in all of the groups were presented with a list of 18 attitudes and asked to indicate which five were the most representative of engineers and then which five were most representative of themselves; groups 1 and 2 answered this question as part of a written survey in fall 2015 while group 3 answered the question as part of interviews in spring 2015. The interview participants explained why they ascribed particular attributes to engineers or themselves. Chi-square tests were used to determine if there were differences in the attitudes identified by students as representative of engineers versus personally $(95 \%$ confidence). The traits most commonly associated with engineers (by $62-49 \%$ of the students) were: thoroughness, commitment, curiosity, persistence, and high expectations. The traits least commonly associated with engineers (by only $4-12 \%$ of the students) were: sensitivity, empathy, fairness, tolerance, and positivity. There were not significant differences in the attitudes identified for engineers based on the gender, major, or rank of the students. The traits most commonly attributed to themselves (by $52-41 \%$ of the students) were: curiosity, respect, commitment, and consideration of others. Differences between the frequency that a trait was attributed to engineers versus personally were found for 10 of the 18 attitudes. On average, students selected two of the same traits for both themselves and engineers. There were some demographic differences in the attitudes that students selected as personally representative. Future work will determine if those with particular personal attitudes and/or perceptions of engineers' attitudes have differential retention in engineering.
\end{abstract}

\section{Background}

Engineering education should strive to educate students across all three domains of Bloom's taxonomy: cognitive (knowledge and intellectual skills), psychomotor (motor-skills), and affective (interest, attitudes, values). When the American Society of Civil Engineers (ASCE) considered the Body of Knowledge (BOK) required for entry into the professional practice of civil engineering in order to meet the challenges of the $21^{\text {st }}$ century, they focused on the cognitive domain, but also acknowledged the value of the affective domain. ${ }^{2}$ The BOK describes the affective domain as "an inseparable complement" to the cognitive domain. ${ }^{2}$ For example, an individual's attitudes, interests, and values determine how their knowledge and skills are applied. Attitudes have also been shown to play an important role in individual aptitude and both individual and group achievement. ${ }^{2,11,27,30}$ Some other educational theories embrace the connection between knowledge and affect more clearly, including the conceive-designimplement-operate (CDIO) taxonomy. ${ }^{6}$ Internationally, there have also been calls for education to consider values and affect. ${ }^{8,13,31,36,39}$ The BOK states "bottom line... the profession wants individuals who possess more than knowledge and skill.", p. 92 
Attitudes were the focus of this study. Attitudes have been associated with the third level of Bloom's taxonomy for the affective domain. ${ }^{2,21}$ This is characterized by an individual demonstrating acceptance, preference for, and commitment to a value. Attitudes are included among the 24 outcomes in the BOK, one among the nine professional outcomes. ${ }^{2}$ The BOK offers what it terms a "partial list" of "significant attitudes... that support the effective practice of civil engineering", including 20 attitudes (Table 1): "commitment, confidence, consideration of others, curiosity, entrepreneurship, fairness, high expectations, honesty, integrity, intuition, judgment, optimism, persistence, positiveness, respect, self-esteem, sensitivity, thoughtfulness, thoroughness, and tolerance." 2, p. 148 Interestingly, the attitude entrepreneurship is omitted from the list in Appendix $\mathrm{O}$ of the $\mathrm{BOK}^{2,}$. ${ }^{172}$; this is perhaps indicative of the difficulty in converging on a single set of appropriate or desirable attitudes. Some of these attitudes are reflective of a "People Mind" as described by Goldberg and Somerville ${ }^{12}$, such as consideration of others.

Despite the seeming certainty of the list of important attitudes that were articulated for civil engineers in the BOK, the attitudes that are perceived to be important for engineers have been debated and discussed for a long time. For example, in 1954 Goshen ${ }^{14}$ discussed a typical "engineer personality" that included precision and meticulousness, intelligence toward mechanical principles, confidence, pride and self-esteem, dependability, sensitivity to criticism, rigidness, knowing little about human principles, difficulty working with others, and resistance to change. The author pointed out the short comings of these attributes with respect to solving "engineering problems today" and called for training engineers to learn about human factors. In 1962, Frye ${ }^{10}$ discussed the attitudes that he felt were important in becoming a successful engineer, from the perspective of industry. Attitude was discussed after ability and drive. The six attitudes promoted were: a desire to get a job done, positive thinking, a big picture view of the problem to be solved, concern for helping the company, humility, and finally ethics and integrity. While some of these older views of engineering are still somewhat relevant today, it is clear that engineers need a different set of attitudes to be successful. ${ }^{25} \mathrm{Newport}^{27}$ tried to determine which attributes were linked to the "effectiveness" of engineers. From open-ended interviews they developed a list of 68 attributes, and then in follow-up surveys with supervisors and engineers found that 34 correlated significantly with effectiveness. Nguyen ${ }^{29}$ compared the extent to which engineers working in industry, engineering academics, and engineering students perceived seven generic qualities and attributes as "essential" for an engineer; attitudes (behavior, thoughts, and actions) were among these seven. Overall, engineers in industry ranked attitudes as the most important among the seven - above technical knowledge and skills, intellectual skills, standards of engineering practice, business practices (which ranked at 92.3 to 66.2, respectively). In addition, engineers in industry rated attitudes significantly more important (96.9) than academics or students (70.6 and 75.7, respectively). The ten attitudes evaluated included competence, integrity, commitment, flexibility, a commitment to life long learning, reliability, tolerance, conscientiousness, approachability, and punctuality (listed in order from highest importance at 87.7 to lowest importance at 24.6 , as ranked by engineers in industry).

Studies that have explored the perceptions of engineering students with respect to the attitudes, values, or characteristics that are important for engineers are not numerous. In the Nguyen ${ }^{29}$ study, the average student ratings of the importance of ten attitudes were the highest for competence and commitment (64.9), followed by integrity, conscientious, reliability, approachability, flexibility, and commitment to lifelong learning (56.8 to 48.6), and the lowest 
ratings for tolerance and punctuality (37.8 and 35.1). Louie ${ }^{20}$ surveyed junior and senior students, and summarized the types of "characteristics" of ideal professional engineers that the students identified in four groups: technical competence including creativity; communication skills for effective teamwork; conscientiousness, diligence, persistence and a drive toward maximal performance; and high moral standards. The third group is quite similar to many of the attitudes that were listed in the BOK, such as commitment, high expectations, persistence, and thoroughness. The fourth group of characteristics seems similar to the attitudes of fairness, honesty, and integrity.

In general, engineering does not seem to readily associate itself with people-oriented attitudes. $^{22,26}$ The distinction between people-orientation and thing-orientation has been proposed as a potential reason for the low percentages of women in engineering. ${ }^{28}$ Hess et al. ${ }^{16}$ documented the minimal use of the terms empathy and care in association with engineering, along with varying perceptions of engineering as empathetic/caring by engineering faculty. They note,

In two of the three sessions, engineering faculty participant responses tended to vacillate between minimizing and dismissing the presence of care/empathy within the practice of engineering (industry and academic) and their teaching - although not explicitly stating whether or not they personally believed it should be present or not. ${ }^{16, \text { p. } 15}$

However, the growth of humanitarian programs in engineering education and practice, including Engineers Without Borders (EWB), perhaps points to the importance of people-oriented attitudes for some engineers. ${ }^{18,19}$ The research of Litchfield and Javernick-Will ${ }^{19}$ found some differences in the characteristics or personas that EWB members attributed to themselves versus engineers in general. For example, humanitarian characteristics (such as caring) were self-descriptors for $34.6 \%$ of the EWB members but only attributed to engineers in general by $8.2 \%$; curious was a self-descriptor for $14.7 \%$ of the EWB members, but only used to describe engineers in general by $8.5 \%$; optimistic was used as a self-descriptor by $5.1 \%$ of the EWB members, but only used to describe engineers by $0.2 \%$.

A better understanding of the ways that engineering students view the attitudes, values, and characteristics of engineers and themselves might be helpful in determining threats to developing an engineering identity, and therefore persistence concerns. There have not been many studies exploring links between attitudes and retention. Attitudes related to engineering and confidence were found to relate to persistence among first year students ${ }^{3}$; however, these attitudes are quite dissimilar to the BOK list. Hall et al. ${ }^{15}$ explored personality traits under the Five-Factor Inventory and found that conscientiousness was a predictor of retention in engineering; none of the other traits showed significant correlations to retention. The terms that they associated with conscientiousness included purposeful, strong-will, determined, accomplishment, self-efficacy, and reliability. There are a number of attitudes in the BOK that seem related to conscientiousness including commitment, confidence, high expectations, persistence, and thoroughness. Hall et al. ${ }^{15}$ cites a number of other studies that have linked conscientiousness to academic performance, and conscientiousness is also commonly associated with engineers. ${ }^{40}$ On the other hand, the agreeableness factor -- which includes altruism, empathy toward others, willingness to assist others - only appears to be reflected in one of the twenty BOK attitudes (consideration of others). Agreeableness was found to be lower in engineers than average citizens in the 
Netherlands ${ }^{40}$ and has been theorized to relate to job preference / aptitude in two non-engineering career fields. ${ }^{17}$ Thus, one begins to see that particular attitudes may be more common among engineers than others. It is likely that this reflects a combination of natural traits as well as attitudes that are learned in the process of becoming an engineer.

To what extent should or can engineering education work to instill particular attitudes in students? Interestingly, the BOK states:

Absent a proactive effort at the university level, many civil engineering students and young engineers are not likely to acquire such attitudes - or worse, are likely to acquire negative attitudes. ${ }^{2, \text { p. } 89}$

It is unclear on what basis the authors of the BOK made this statement, however there have been recent findings that point to the potential accuracy of this statement. Cech's work found a "culture of disengagement" in engineering as students progressed through college and into the workforce. ${ }^{4}$ Vesilind and Gunn ${ }^{41}$ also noted potential decreases in individuals' ethical commitment upon entering the engineering workforce. This problem may point to the importance of including affective outcomes in addition to cognitive within the professional and ethical responsibility outcome; in fact, the $\mathrm{BOK}^{2}$ proposed this two-dimensional approach to this outcome (p. 94). Further, fairness, honesty, and integrity are important elements of ethical behavior and these are also listed among the attitudes that the BOK describes as significant.

This research explored the extent to which engineering students believed that various attitudes were characteristic of both engineers and themselves. If students perceive similarities in what they believe are predominant characteristics of both engineers and themselves, they may identify to a greater extent with engineering; this identity may translate into persistence to graduating with engineering degrees. Conversely, differences in their perceptions of engineering characteristics and their own personal characteristics may lead to feelings of a poor fit with engineering, putting these students at greater risk for leaving engineering. ${ }^{32}$

This research explored the perceptions of engineering students with regards to attitudes that were most characteristic of engineers and themselves. The research questions explored were:

(1) Do students identify similar traits as characteristic of both engineers and themselves?

(2) Are particular attitudes commonly associated with engineers, with "people-focused" attitudes less common than other attitudes?

(3) Is there evidence that alignment or differences in the attitudes selected by the students as most important for engineers and themselves may impact intent to remain in engineering?

\section{Methods}

The first task of the research was to develop a list of attitudes to explore. The goal was to provide students with a breadth of options, but a list that was not overwhelmingly long. The process began with the 20 attitudes listed in the ASCE BOK ${ }^{2}$ (Table 1). From among this list, five were excluded: entrepreneurship, honesty, intuition, optimism, and self-esteem. These attitudes were excluded for the following reasons. Entrepreneurship was itself omitted in the BOK discussion in Appendix $\mathrm{O}$; this characteristic is often less associated with civil and environmental engineering (the main targeted disciplines in this research) as compared to other engineering disciplines; as 
such, it was omitted. Honesty is similar to the attitude of integrity; it has been stated that integrity requires honesty ${ }^{9}$, therefore this higher ideal of integrity was retained in the study. Intuition is frequently discussed in the context of judgment, and was therefore omitted as somewhat overlapping this idea. Optimism was excluded due to perceived similarity with the attitude of positivity that was also on the BOK list and included in the study. Self-esteem seemed somewhat related to confidence. Three attitudes were added: care, empathy, and flexible. The first two attitudes have been explored in previous research and found to be infrequently associated with engineers, ${ }^{16,35}$ but seem important in the context of humanitarian and peoplecentric engineering. These attitudes also seem to align with studies that have characterized individuals in Generation Y/Millennials as wanting to make a difference and help others. ${ }^{5,33}$ Millennials have also be characterized as confident, optimistic, social, and having high expectations, ${ }^{24}$ traits that are largely reflected in the BOK attitudes. Flexibility has been indicated as important to professionals $1,27,29,38$ and was thus included in the study. Note that a number of these attitudes also map to ideas encompassed within the Big Five personality traits. ${ }^{7,31}$

Table 1. Attitudes in the BOK and Survey

\begin{tabular}{|c|c|c|c|}
\hline $\begin{array}{c}20 \text { ASCE } \\
\text { BOK attitudes }^{2}\end{array}$ & $\begin{array}{l}18 \text { attitudes } \\
\text { on Survey }\end{array}$ & $\begin{array}{l}\text { Related } \\
\text { Ideas }\end{array}$ & $\begin{array}{l}\text { Previous Studies } \\
\text { \& endorsements }\end{array}$ \\
\hline & Care & Humanitarian engrg. & 44 \\
\hline Commitment & Commitment & & 29 \\
\hline Confidence & Confidence & & 6,38 \\
\hline Self esteem & & & 27 \\
\hline Consideration of others & Consideration of others & Agreeableness $^{31}$ & 27 \\
\hline Curiosity & Curiosity & Openness ${ }^{31}$, Inquisitive & $6,23,27,37,38$ \\
\hline & Empathy & Agreeableness 31 & 7 \\
\hline Entrepreneurship & & & 13,27 \\
\hline Fairness & Fairness & & 43 \\
\hline & Flexible & Adaptability $^{31}$ & $6,25,27,29,38$ \\
\hline High expectations & High expectations & & \\
\hline Honesty & & & 43 \\
\hline Integrity & Integrity & & $6,27,29,43$ \\
\hline Intuition & & & 27 \\
\hline Judgment & Judgment & & 6,27 \\
\hline Persistence & Persistence & Perseverance $^{6}$ & $6,42,43$ \\
\hline Optimism & & General mood ${ }^{31}$ & 27 \\
\hline Positivity & Positivity & & \\
\hline Respect & Respect & & $25,27,38,43$ \\
\hline Sensitivity & Sensitivity & & 43 \\
\hline Thoughtfulness & Thoughtfulness & & \\
\hline Thoroughness & Thoroughness & Conscientiousness ${ }^{7,31}$ & $27,29,43$ \\
\hline Tolerance & Tolerance & & 29,43 \\
\hline
\end{tabular}

Three groups of students participated in the study: (1) first year civil, environmental, and architectural engineering students attending a large, public, research-intensive institution; (2) senior civil engineering students attending a large, public, research-intensive institution; and (3) 21 students at the end of their junior year of college (pursuing seven different engineering majors 
at five different institutions). Groups 1 and 2 were given a paper-version of a 2-page survey on the first day of class in fall semester 2015, and could complete the survey for class extra credit (as one among multiple extra credit options available over the course of the semester). The survey began with an informed consent statement. The groups of students were presented with an alphabetized list of 18 attitudes and asked to indicate which five were most representative of engineers and then which five were most representative of themselves. The attitude selection was the second question on the survey, immediately following a question that asked the students to rate the importance of different knowledge and skills for professional engineers. The response rates to this survey were: $86 \%$ of civil engineering first year students, $77 \%$ of first year architectural engineering students, $77 \%$ of environmental engineering first year students, $63 \%$ of civil engineering seniors. Group 3 were asked the question about representative attitudes as a small part of an hour-long interview; these students had been participating in yearly longitudinal interviews with $\$ 100$ incentives for each interview since spring 2013.

As part of a homework assignment in week 10 of the fall semester, the first-year civil and architectural engineering students in Group 1 were asked to select five attitudes from the ASCE BOK that they believed were most important for professional engineers and describe why they believed each was important; this was included within an assignment on professionalism and ethics, which may have biased responses toward "ethically-oriented" attitudes. The requirement for the students to describe "why" also provides insight into their reasoning. This was the second time in the semester that the students in the course had been directed to read portions of the BOK; the first assignment due in week 3 of the semester also asked students to consider the BOK outcomes. An entire lecture which discussed the BOK, including the attitude outcome, preceded that first assignment. The student responses on the ethics homework assignment will be compared and contrasted with the survey responses from these same students at the beginning of the semester.

The civil engineering seniors (Group 2) were participating in a new Professional Issues course. The majority of these students had transferred into the program at some point, and therefore had missed instruction on professional licensure, ethics, and sustainability in the first year introduction to civil engineering course. As part of the instruction in the Professional Issues course, the students were required to read and discuss the ASCE BOK. As part of this assignment, they were asked to first map their courses and co-curricular experiences to the 24 BOK outcomes and levels of achievement. A later question asked the students to list the five attitudes that they believed were most representative of professional civil engineers and five attitudes they believed were the most representative of themselves. They were also asked to discuss any important attitudes for professional engineers or themselves that they felt were missing from the BOK. In this context, they had access to the full BOK list and could choose or not to articulate additional attributes. This allowed some comparison between the attitudes selected from among the "modified" list of 18 that were presented on the day 1 optional survey versus the 20 attitudes articulated in the BOK.

Group 3 students were participants in a longitudinal study on social responsibility; that study is described more fully in Rulifson et al. ${ }^{34}$ The 21 students were majoring in civil engineering (8), environmental engineering (1), architectural engineering (1) mechanical engineering (7), computer science (2), and chemical engineering (2). Twelve women and nine men were 
interviewed. They attended a large public university (5), a technical university (8), a mediumsized, public, research university (2), a private university (5), and a small public undergraduate university (1). The interviews were conducted over the phone in spring 2015, when the students were at the end of their third year in college. The full interviews were about 1-hour in duration. Prior to the start of the interviews, the students read, signed, and emailed the informed consent form. During a small, early part of the interview, the students were emailed the list of 18 attitudes. The students were asked to identify the five attitudes that they believed were most representative of engineers and themselves. They were asked if there were any important attitudes that were not on the list. The students were also asked to explain why they had selected a couple of the attitudes that they had identified. The interviews were audio recorded and transcribed into written documents using Nuance Dragon software. Each student was assigned a pseudonym, by which they will be referred in this paper.

The data from the surveys and interviews were entered into a spreadsheet, along with basic demographic information for each student (major, gender, institution). Comparisons between groups were made on the basis of chi-square tests in Excel with 95\% confidence used for statistical significance. IBM SPSS v. 23 was used to conduct other non-parametric statistical tests. Quotes from the homework assignments and interviews will be provided to contextualize the quantitative data, and show how the students defined the terms and why they attributed the characteristics to engineers and/or themselves.

\section{Results and Discussion}

\section{Alignment between personal and engineer attitudes}

The number of traits that were identified by the students as most representative of both engineers and themselves varied from 0 to 5 . The average number of traits identified by an individual as both personally characteristic and representative of engineers was the highest among architectural engineering first-year students and juniors, and the lowest among first-year environmental engineering students (Table 2). A Kruskal-Wallis test found a statistically significant difference between majors, with sig. 0.009; post-hoc paired tests determined that architectural and environmental students were significantly different (adj. sig. 0.009). There was not a significant difference between the male $(\mathrm{n}=75 ;$ median $=2)$ and female $(\mathrm{n}=73$; median $=2)$ students (independent samples Mann-Whitney U test sig. 0.185).

Table 2. Number of Attitudes that Individuals Identified as Most Characteristic Personally and for Engineers

\begin{tabular}{|lcccc|}
\hline Student Group & n & Average & Minimum & Maximum \\
\hline 1. First-year architectural & 20 & 2.56 & 1 & 4 \\
1. First-year civil & 54 & 2.04 & 0 & 5 \\
1. First-year environmental & 49 & 1.76 & 0 & 4 \\
3. Juniors in various majors & 21 & 2.52 & 1 & 4 \\
2. Senior civil (survey) & 12 & 1.90 & 1 & 3 \\
\multicolumn{1}{c}{$\quad$ (homework) } & 16 & 2.31 & 1 & 5 \\
\hline
\end{tabular}




\section{Common attitudes}

The fraction of all 156 students who rated the attitudes as most characteristic of engineers and themselves are shown in Table 3. The attributes are organized in the table from most to least commonly ascribed to engineers; attributes in bold were the top six most common personal characteristics. Highlights in yellow indicate that students more frequently identified this attribute as characteristic of engineers than themselves (based on chi-square test $p<0.05$ ); this was true for thoroughness, judgment, and commitment. These appear to align with a stereotype of engineers as hard-working and dedicated. Highlights in green indicate that the students more frequently identified this as a personal attribute compared to characteristic of engineers. The largest differences of this type (31-19\%) were for respect, consideration of others, positivity, empathy, and care. Four of these five attributes are people-oriented. This shows that the students perceived themselves as possessing important people-centric attitudes, to a larger extent than they believed that these attitudes characterized engineers.

Table 3. Frequency that students identified 18 attitudes as characteristic of engineers and themselves

\begin{tabular}{|lccc|}
\hline Attitude & $\begin{array}{c}\text { \% Students identified as } \\
\text { characteristic of engineers }\end{array}$ & $\begin{array}{c}\text { \% Students identified } \\
\text { as characteristic of self }\end{array}$ & $\begin{array}{c}\text { Chi-square } \\
\text { test sig. }\end{array}$ \\
\hline Thoroughness & 62 & 24 & $<0.001$ \\
Commitment & 62 & $\mathbf{4 4}$ & 0.029 \\
Curiosity & 58 & $\mathbf{5 2}$ & 0.491 \\
High expectations & 49 & $\mathbf{3 7}$ & 0.084 \\
Persistence & 49 & 35 & 0.054 \\
Integrity & 42 & 31 & 0.110 \\
Judgment & 30 & 11 & $<0.001$ \\
Confidence & 28 & 21 & 0.204 \\
Thoughtfulness & 27 & 30 & 0.596 \\
Consideration of & 25 & 51 & 0.014 \\
others & 21 & 25 & 0.406 \\
Flexible & 19 & $\mathbf{5 0}$ & $<0.001$ \\
Respect & 13 & 32 & $<0.001$ \\
Care & 12 & $\mathbf{3 7}$ & $<0.001$ \\
Positivity & 10 & 16 & 0.160 \\
Tolerance & 6 & 17 & 0.003 \\
Fairness & 4 & 24 & $<0.001$ \\
Empathy & 4 & 11 & $<0.001$ \\
\hline Sensitivity & 12 & 25 & \\
\hline
\end{tabular}

Bold text $=$ among top six most common attributes for self; yellow highlight $=$ more common for engineers than self; green highlight $=$ more common for self than engineers;

Various demographic factors were examined to explore whether different types of students differentially identified particular attributes as representative of engineers. There were no statistical differences between male and female students (chi-square test sig. 0.16-0.99). Among the first-year students there were not statistical differences between the three majors; respect was potentially higher among civil engineering students (28\%) compared to environmental (14\%) and architectural (5\%) (chi-square test sig. 0.086). There were also not statistical differences 
between first year and senior civil engineering students; curiosity may be more common among first year students than seniors (57\% vs. 17\%, chi-square test sig. 0.071). Differences among the juniors between mechanical $(n=6)$ and civil $(n=8)$ were not found; mechanical engineering students attributed judgment to engineers somewhat more than civil engineering students (100\% vs. $25 \%$, chi-square test sig. 0.066 ).

Not surprisingly, there were differences in the frequency that some attitudes were selected as personally representative by students in different demographic groups. Male students $(n=83)$ were more likely to describe themselves by the attributes integrity $(42 \%)$, flexible $(33 \%)$, and judgment $(16 \%)$ compared to female students $(n=73 ; 18 \%, 16 \%, 5 \%$, respectively; chi-square test sig. 0.006, 0.045, and 0.054). Among first-year students, integrity was the only attitude that differed significantly between majors; $52 \%$ civil, $20 \%$ architectural, $16 \%$ environmental (chisquare test sig. 0.004). Senior civil engineering students were more likely to characterize themselves as thorough (67\%) compared to first year civil engineering students $(22 \%)$ (chisquare test sig. 0.011).

\section{People-oriented attitudes}

A number of the attitudes have apparent similarities. There appears to be a cluster of attitudes that relate to a "people mind", including consideration of others, empathy, respect, sensitivity, tolerance, fairness, care, and thoughtfulness. There also appears to be a cluster of attitudes that relate to delivering "quality work", including commitment, high expectations, persistence, thoroughness, judgment, integrity, care, and thoughtfulness. Note that two of the attitudes are somewhat ambiguous and therefore could fit either cluster. For example, care could be conceptualized as being concerned for other people or being concerned for the quality of one's work. Similarly, thoughtfulness could be directed toward people or one's technical work. Given these ambiguities, six attributes for "people mind" and six attributes for "quality work" were clustered and explored (Table 4).

Table 4. Percentage of students selecting attitudes representative of people mind and quality work

\begin{tabular}{|c|c|c|c|c|}
\hline $\begin{array}{l}\text { Attitude } \\
\text { cluster }\end{array}$ & Attitudes & $\begin{array}{l}\text { Selected } \\
\text { for }\end{array}$ & $\begin{array}{l}\% \text { students with } \\
1 \text { or more of } \\
\text { these } 6 \text { attitudes }\end{array}$ & $\begin{array}{l}\text { Median } \\
\quad \# \\
\text { attitudes }\end{array}$ \\
\hline People mind & \multirow{2}{*}{$\begin{array}{c}\text { consideration of others, } \\
\text { empathy, respect, sensitivity, } \\
\text { tolerance, fairness }\end{array}$} & Engineers & 49 & 0 \\
\hline People mind & & Personally & 83 & 1 \\
\hline Quality work & \multirow{2}{*}{$\begin{array}{l}\text { thoroughness, commitment, } \\
\text { high expectations, persistence, } \\
\text { integrity, judgment }\end{array}$} & Engineers & 97 & 3 \\
\hline Quality work & & Personally & 84 & 2 \\
\hline
\end{tabular}

When describing engineers, about half of the students selected one or more of the six attitudes associated with a "people mind", while nearly all (97\%) selected one or more of the six "quality work" attitudes. Forty-eight percent of the students identified one or more attitudes from both categories among their characteristics of engineers. But $87 \%$ of the students selected more "quality work" attitudes than "people" attitudes as characteristics of engineers; only $3 \%$ of the students selected more "people" attitudes than "work" attitudes for engineers. Among the students, a median of three of the six "quality work" attitudes were among the five attitudes 
selected as most characteristic of engineers, versus a median of zero of the six "people mind" attitudes. There were not significant differences by gender (independent samples Mann-Whitney U test, sig. 0.689-0.995) or between majors (Kruskal-Wallis sig. 0.913, 0.105). These results follow historical stereotypes of engineering as a profession that requires hard work and tends to be less people oriented as compared to many other jobs.

In contrast, the majority of the students $(\sim 83 \%)$ identified attitudes representative of a "people mind" and "quality work" as personally relevant; $67 \%$ identified one or more of the attitudes representative of both the people and work clusters. For personal attitudes, $44 \%$ of the students selected more of the six "work" attitudes than the six "people" attitudes; $31 \%$ of the students selected more people attitudes; $25 \%$ selected the same number of attitudes from both the people and quality work clusters. There were not significant differences in the clusters of attitudes selected by male vs. female students; there were not significant differences in the number of people attitudes selected by students in different majors (Kruskal-Wallis sig. 0.404); there was a significant difference between majors for the number of work attitudes selected as characteristic of themselves (Kruskal-Wallis sig. 0.002; environmental average 1.3 vs. civil average 1.8, posthoc adjusted significance 0.015 ).

The results indicate that personally individuals select a more balanced set of people-oriented and quality work attitudes, in contrast to the quality work attitudes that most believed dominated engineers' attitudes. This difference could be due to the persistence of long-held stereotypes of engineers, as compared to the typical values of the Millennial Generation. Alternatively, this newer generation may begin to change the culture of the engineering profession, such that in the future engineering becomes more people-oriented.

\section{Traits selected among $20 \mathrm{BOK}$ outcomes}

The attitudes that the students selected as representative of engineers as part of a homework assignment based on reading the ASCE BOK are summarized in Table 5. The three pairs of attitudes that seemed closely aligned from the BOK (integrity/honesty, optimism/positivity, confidence/self-esteem) are shown as both combined clusters and well as individually; note that some students selected both characteristics, and that is why the individual numbers don't sum to the combined total.

Table 5. Percentage of students who identified attitudes within the BOK as representative of engineers and/or self

\begin{tabular}{|c|c|c|c|c|c|c|}
\hline $\begin{array}{c}20 \text { ASCE } \\
\text { BOK attitudes }\end{array}$ & \multicolumn{2}{|c|}{$\begin{array}{c}\text { Most important for } \\
\text { engineers } \\
\text { \% First year students } \\
\mathrm{N}=48\end{array}$} & \multicolumn{2}{|c|}{$\begin{array}{c}\text { Representative of } \\
\text { Engineers } \\
\% \text { Seniors } \\
\mathbf{N}=17 \\
\end{array}$} & \multicolumn{2}{|c|}{$\begin{array}{c}\text { Representative } \\
\text { of Self } \\
\% \text { Seniors } \\
\text { N }=17 \\
\end{array}$} \\
\hline Integrity & & 52 & & 65 & & 35 \\
\hline Honesty & 17 & 52 & 70 & 23 & 47 & 29 \\
\hline Commitment & \multicolumn{2}{|c|}{58} & \multicolumn{2}{|c|}{47} & \multicolumn{2}{|c|}{18} \\
\hline Thoroughness & \multicolumn{2}{|c|}{44} & \multicolumn{2}{|c|}{59} & \multicolumn{2}{|c|}{35} \\
\hline Consideration of others & \multicolumn{2}{|c|}{40} & \multicolumn{2}{|c|}{35} & \multicolumn{2}{|c|}{35} \\
\hline Curiosity & \multicolumn{2}{|c|}{35} & \multicolumn{2}{|c|}{24} & \multicolumn{2}{|c|}{41} \\
\hline Optimism & 33 & 27 & 18 & 6 & 12 & 6 \\
\hline
\end{tabular}




\begin{tabular}{|c|c|c|c|}
\hline $\begin{array}{c}20 \text { ASCE } \\
\text { BOK attitudes }\end{array}$ & $\begin{array}{c}\text { Most important for } \\
\text { engineers } \\
\text { \% First year students } \\
\mathbf{N}=\mathbf{4 8}\end{array}$ & $\begin{array}{c}\text { Representative of } \\
\text { Engineers } \\
\% \text { Seniors } \\
\mathbf{N}=17\end{array}$ & $\begin{array}{c}\text { Representative } \\
\text { of Self } \\
\% \text { Seniors } \\
\text { N }=17\end{array}$ \\
\hline Positivity & 6 & 12 & 6 \\
\hline Confidence & 29 & 6 & 29 \\
\hline Self esteem & 4 & 12 & 12 \\
\hline Respect & 31 & 35 & 18 \\
\hline Persistence & 31 & 24 & 41 \\
\hline Judgment & 27 & 41 & 24 \\
\hline High expectations & 15 & 35 & 41 \\
\hline Tolerance & 15 & 6 & 12 \\
\hline Thoughtfulness & 13 & 24 & 18 \\
\hline Fairness & 10 & 12 & 0 \\
\hline Intuition & 8 & 18 & 35 \\
\hline Entrepreneurship & 0 & 6 & 6 \\
\hline Sensitivity & 2 & 0 & 29 \\
\hline
\end{tabular}

Green highlight is more common attribute personally vs. for engineers; chi-square $\mathrm{p}<0.05$

The first year students likely read a more limited part of the BOK as compared to the seniors. The first year students were introduced to the BOK in week 2 of the semester, in the context of the outcomes needed prior to licensure and how they had been designed into their curriculum. As part of the ethics homework when the students selected the five attitudes perceived to be the most important for engineers, the first year students were considering the process and purpose of licensure itself, in regards to helping to ensure public safety and societal well-being. The senior students had been discussing ethics and societal impacts in-class during the weeks that preceded the homework assignment where they selected characteristic attitudes. Chi-square tests did not find statistically significant differences in the response frequency between the first year students and seniors for any of the 20 attitudes.

There were similarities in the "top five" most important attitudes for engineers as rated by the first year students and seniors - both groups included integrity/honesty, commitment, thoroughness, and consideration of others; the first year students also included curiosity, while the seniors included judgment. These results reflect a higher percentage of students selecting integrity compared to the $42 \%$ of the students who selected integrity of characteristic of engineers on pre-survey at the beginning of the semester with 18 attitudes. Further, more students rated consideration of others in the top five important traits for engineers on the homework (35-40\%) as compared to the pre-survey (25\%). Thus, it is possible that the context of $\mathrm{BOK}$ and the courses, which included a focus on the importance of engineering to society, may have impacted students' opinions. Commitment and thoroughness were similarly prevalent on the homework and the pre-survey, in the top four most commonly cited by students in both cases.

On the homework assignments, there were similarities in the attitudes that were least frequently associated with engineers by both the first year and senior students - both groups included sensitivity, entrepreneurship, and fairness among the five least common attitudes. Sensitivity and 
fairness were also among the five attitudes least commonly associated with engineers on the presurvey.

When the attitudes were clustered into "people mind" and "quality work", the results were similar to what was found on the pre-survey (Table 6). For engineers, attitudes characteristic of quality work were cited more frequently than people-oriented attitudes. Among the first year students, $65 \%$ selected more attitudes characteristic of "quality work" as compared to "people mind", while 15\% selected more attitudes characteristics of a "people-mind". Among the seniors, $71 \%$ selected more of the "quality work" attitudes as representative of engineers compared to the people mind attitudes; $6 \%(\mathrm{n}=1)$ selected more people mind traits; $24 \%$ selected the same number of quality work and people attitudes. For personally representative attitudes, $65 \%$ of the seniors selected more "quality work" attitudes than "people-mind" attitudes; but 24\% selected more "people-mind" attitudes; $12 \%$ selected an equal number of the quality work and peoplemind attitudes. This indicates that some individuals with a fairly strong people-orientation remained in engineering to their senior year, although individuals with a greater focus on quality work attitudes outnumbered the people-focused civil engineering students.

Table 6. Selection of attitudes indicative of people mind vs. quality work among the $20 \mathrm{BOK}$ attitudes by students on homework assignments

\begin{tabular}{|lcccccc|}
\hline $\begin{array}{l}\text { Attitude } \\
\text { cluster }\end{array}$ & $\begin{array}{c}\text { Selected } \\
\text { for }\end{array}$ & $\begin{array}{c}\text { \% first year } \\
\text { students one } \\
\text { or more of 5 } \\
\text { or 6 attitudes }\end{array}$ & $\begin{array}{c}\text { \% senior } \\
\text { students one } \\
\text { or more of 5 } \\
\text { or 6 attitudes }\end{array}$ & $\begin{array}{c}\text { First year } \\
\text { students } \\
\text { median \# } \\
\text { attitudes }\end{array}$ & $\begin{array}{c}\text { Seniors, } \\
\text { median } \\
\text { attitudes }\end{array}$ & $\begin{array}{c}\text { \% seniors } \\
\text { predominant } \\
\text { attitude }\end{array}$ \\
\hline People & Engineers & 75 & 65 & 1 & 1 & 6 \\
mind & Personally & N/A & 65 & N/A & 1 & 24 \\
\hline Quality & Engineers & 96 & 94 & 2 & 3 & 71 \\
work & Personally & N/A & 94 & N/A & 2 & 65 \\
\hline
\end{tabular}

N/A - not available; the first year students were not asked to identify personally representative attitudes on their homework assignment

Among senior civil engineers, seven (of the 18 who completed the assignment) indicated some attributes of professional civil engineers that they thought were missing from the BOK list. These included: awareness, foresighted, humble, intellectual, negative attitudes (anger, judgmental, stress), neutrality, punctual, responsive, and resourceful. For example, one student noted:

One important attitude for professional engineers that I think might be missing is "foresighted." In matters of design and sustainability, it is important for a civil engineer to be able to project into the future and anticipate future needs.

Only three senior civil engineering students indicated personal attitudes that were important and missing. There attitudes were: awareness, compassion, kindness; critical, inquisitive, probing, skeptical; and passionate. These students indicated why these attitudes were also important for engineers. For example, one student noted: "I believe compassion should be part of the BOK as that is inherent to watching the welfare of the common good."

On another part of the homework assignment, the seniors identified where they had learned to reach each of the BOK outcomes to various levels of achievement. For the attitude outcome, ten 
students (of 19) listed the professional issues course; courses listed by two or more students included senior design, introduction to construction, introduction to civil engineering, and project management 1. A variety of co-curricular activities were also listed; three students noted internships, one Association of General Contractors (AGC), one research, and one Panhellenic president. So some students were more broadly aware, rather than considering only a course with a subject explicitly titled "attitudes". I suspect that the students actually learned these attitudes through a vast array of both course and co-curricular experiences, but many did not reflect on it deeply as part of the assignment where they were filling in a table that mapped courses/experiences to BOK outcomes and LOAs.

\section{A richer perspective on people-oriented attitudes}

The student interviews provide insight into why students identified particular attitudes as representative of themselves or engineers. Previous research has found that empathy is not typically associated with engineers. Among the 21 junior students interviewed, Travis was the only one to select empathy among the top five attitudes that he associated with engineers. Travis had been majoring in civil engineering for two years at a medium-sized public university, but at the time of the interview was not attending college. He was asked why he chose empathy (I = interviewer):

I: Will you tell me kind of about the empathy one that you chose for engineers and why you think that is one of your top five words to describe them?

Travis: I guess, well one the fact that I noticed it covered multiple ones. I think that's maybe what made me really pick it is that empathy is a really general notion that can involve a lot of positive outcomes, um, and it's something that without it, you won't be able to consider the people in the community and the animals and nature that you are affecting.

I: Yeah all right. And how do you see, where kind of did you learn this and where do you see engineers being empathetic?

Travis: Ummm, I guess with like, the waste we have today, I mean it's sort of hypocritical almost, the fact that we are just doing it now and cleaning up after the mess we've already made and that kind of thing, but the fact that we are empathetic towards the nature and the animals that we have really destroyed and ruined with things in the past, I think now engineers are trying to find ways to fix that and to turn it back around. I guess an example of that would just be like waste disposal and aeration piles and things like that that are reusable and they create something out of trash. It's not just a trash pile, it's something that produces something positive.

Brandon, a student majoring in civil engineering at a technically-focused institution, selected empathy as an attitude representative of himself but not among the top five that he selected for engineers. However, as he was describing the attitudes that he selected as most representative of engineers he concluded with "But I guess all of them apply in some way, but those are the ones as far as the job goes." Brandon was asked to explain his ideas about empathy more:

I: So can you talk to me a little bit about empathy... and why that's important?

Brandon: Sure yeah. Why it's important? I don't know, it's...I don't know, what would life be without empathy? I don't know if it's just sort of everything is set up by it isn't it? If you did everything without the consideration of what is going to happen to anybody else things wouldn't be good I guess.

I: So what is empathy to you? What does that mean? 
Brandon: Well for that, you just have to sometimes put yourself in somebody else's shoes in terms of what you're talking about or doing or saying or the way that you are acting. And not necessarily the thoughts but just the way that you present yourself to I guess, the world and other people.

I: Do you think that fits in with engineering or engineers' characteristics very well?

Brandon: I think so. There's got to be a point where you have to weigh it and see what's more important than the other thing. But I would say it's pretty important in some decisions and I guess it depends on what you are working on too, but more so the field that I'm going into the same mechanical that is just going to build little things. Or maybe not. Because it could end up hurting somebody, but it's just larger scale in terms of civil and dealing with land and people, places that are important to people. The way things were and the way things are and the way things are going to be now and in the future.

Nathan was another student who identified empathy as an attitude characteristic of himself but not for engineers as a whole. Nathan was majoring in civil engineering at the technically-focused university.

I: So three of five are matching, and you said empathy first [for yourself] which I think is interesting and you did not put that in with engineers list. So how do you, like just tell me about that what you think about that?

Nathan: I don't know, I guess I certainly think it's a good quality to have but I'd say it's one of the qualities that I like the most out of myself and I think that it would definitely be good for engineers to have, uhh but what did I say for engineers? Integrity, thoroughness, consideration of others, persistence, and...

I: Commitment. Does empathy fit in there, just not in the first five for you?

Nathan: Yeah I think it's definitely important, but I was trying to go with kind of something that would make a good engineer in general.

I: How do you act on that empathy? Like how are you an empathetic person?

Nathan: I don't know, I feel like I can put myself in most people's shoes fairly well and I can relate to people's situations and try to help them out. I have a friend who just broke his femur a couple weeks ago skiing. And yeah, it was a pretty intense accident but I was able to help him out a lot just to take the time out to go over and help him with homework and give him the notes for classes he missed and stuff like that. And I think that was because I was in the hospital for a while in high school so it was easy for me to put myself in his shoes to try to help him out the way that I thought he would need it or appreciate it the most I guess.

I: Yeah and how about like, you traveled to Guatemala when you were younger right? Nathan: Yeah between seventh and eighth grade.

I: So can you think back to that time and consider how empathy fits into that for you? Nathan: I would definitely say that it made me more empathetic being able to see all the people there who don't have as much as we have in the US, just in general people don't have what they need, so being able to see all of that and go to the orphanage and see everybody with my sister I think that definitely made me more empathetic and to see that and people I guess. I don't know, you know, what else.

I: Are you, is it a priority of yours to be empathetic as an engineer?

Nathan: I don't know if it's a conscious thing, but I definitely would like it to be. 
I: Is there anything in your classes or maybe in your internship that you are working on where that empathy was helpful or important?

Nathan: I think definitely in one of my classes that I took last semester called professional practice where we focused mostly on ethics and morals in engineering, so we were given documents or movies that we're supposed to watch and we would have discussions the whole time. They would ask questions and try to initiate discussion with the class. So I would say that it definitely helped me and my class to form my responses.

Jolene was another student who selected empathy as a personal attitude but not for engineers. She was asked to explore this idea:

I: ....and then what about the empathy one [for you and not engineers]? Do you see much of that being part of engineering?

Jolene: I think it is a big part because of, you know what is your purpose in engineering. I know that I am pretty apathetic when it comes to people and so it is part of what drives me to be an engineer and to have that education so that I can assist them in ways that may be other people couldn't. So I think it's just like what you want to do with engineering. You can be an engineer, but what are you going to do about it?

I: That still sounds pretty personal, though.

Jolene: Yeah, that's true. I chose more personal things for my top five.

I: I'm just wondering if you see much of the empathy in engineering.

Jolene: I think there are definitely sides where engineers, like engineering firms take on projects that are beneficial towards other people. I mean, that's more consideration of others in a way because empathy is more like you putting yourself in other people's shoes type thing. So some of the people in the company may feel that way but I think in general engineers may be more driven, for maybe improving and designing than necessarily always, you know, putting themselves in the situation. So I wouldn't necessarily classify that as all engineers need to be empathetic.

So all of these students, when queried, described how engineers need to consider others, but differed in the extent to which they believed that empathy was of critical importance to engineers.

Shawn, a student majoring in chemical engineering at the large public university, was asked to discuss respect. This attitude was on his personal list but not among those he selected as most characteristic of engineers, although he noted "I feel like all of those apply to engineers just about as well, and it's hard to confine to the five. I guess this is prioritizing them."

I: So can you talk a little bit about that respect one and why it's important to you?

Shawn: You know, I think it's really important and that I think it goes with empathy but you have to take a look at what your actions, or what are the consequences of those and how those are going to affect other people. You know, you have to have a respect for, respect for what you are doing, let me think, I don't know I just try to put things in perspective, I don't know. You sort of have to get away from your own feelings and your own self and kind of look at things on a broader scale and you know, how they're going to affect people and affect science and stuff in the world.

Yeah, I think it's just a lot of thinking from someone else's perspective and what you do to them and what your actions will do to other people. When you're in a meeting you 
may hold back from saying something because of respect for someone else, but I don't know.

I: Yeah, and all of those things that you are doing is out of respect for others. I think that makes sense. Do you feel like that fits pretty well with engineers as well?

Shawn: Oh yeah, respect is one of those that I would've had on there.

Consideration of others was another people-oriented attitude, but it was much more commonly associated with engineers by the students than empathy or respect; five of the juniors interviewed selected this attitude for engineers. Derek, a junior majoring in mechanical engineering at a private institution, identified this attitude for himself but not engineers; he was asked about it:

I: All right, how about the consideration of others?

Derek: Actually, it probably is pretty important especially in thinking of everything that engineers design is for others so you kind of have to consider them. So that is a really big one. I mean, it's hard because they are all really good words that you should use in your job and everything and in your life, so just I kind of picked five of them doesn't necessarily mean that I don't think that they apply more than the others. I just think that the others are more specific to it. But consideration of others I think is certainly important especially in the human factors class that I'm taking right now, it really shows that it's all about people. A lot of times for engineers, you could think about working on a little product that you use around the house or by yourself, there's not a lot of projects that you do that are for other people. I feel like the large majority of what we do is working for other people so you have to take them into consideration. Otherwise what you do is not the best it could be. It doesn't work the best....

So the discussion with a number of students revealed that they would not say that various people-oriented attitudes are not representative of engineers, but they were perhaps left out when they were required to limit their selection to only five attitudes. Further, most of the students articulated why it was important for engineers to have one or more people-oriented attitudes. This may represent a change, where this new generation of future engineering professionals will place a greater emphasis on the people-side of engineering. This movement seems to already be in-progress, given the growth in humanitarian activities in engineering (EWB-USA professionals and similar groups).

\section{Is alignment of perceived attitudes necessary for retention?}

When confronted with the fact that they identified different attitudes as representative of engineers vs. themselves, most of the junior students did not evidence particular concern. Generally the students appreciated that their personal attitudes would make them strong engineers, and they didn't need to conform to the average or stereotypical engineer. Three of the 21 students had only a single attitude in common between those they selected as representative of engineers and those they selected as personally relevant; another six students selected two of the same attitudes.

For example, Derek was majoring in mechanical engineering at a private university and had only a single common attitude between those he selected as representative of engineers and himself (engineers: curiosity, judgment, thoroughness, high expectations, persistence; self: 
consideration of others, positivity, high expectations, commitment, integrity). The interviewer (I) asked him about this:

I: So you only have one that matches.

Derek: I noticed that.

I: What's up with that?

Derek: I don't know. I think maybe my thought process when I was thinking of the ones for the engineers, these are the ones that engineers, well it kind of distinguishes them a little more. And then I feel like I have some of those traits, but those are not necessarily my distinguishing factors.

Brandon was another student with only one attitude in common between those selected for engineers and those he selected for himself (engineers: high expectations, flexible, integrity, care, confidence, "I guess all of them apply in some way"; self: flexible, persistence, positivity, empathy, and tolerance)

I: You only have one that matches between the two.

Brandon: Yeah I guess.

I: ... So it's kind of interesting though, you've been in engineering for a while and I think you clearly think of yourself as an engineer in some ways, so can you just talk to me about that, like how you feel, what you think about the difference I guess in that flexible is the only one that overlaps in this top five that you have?

Brandon: That's true, I guess that's the biggest one I suppose. I don't know, I guess it's more of a choice thing for me than nature. I guess it's because people could say yeah I'm this by nature you know, because that's just the way I am. I don't really have a sense of that for anything really strongly. I just got done talking to you about how I do band all the time, I don't know, and then at the same time I had two jobs and was thinking about engineering at the same time every day. So I would have to go and speak that language and then I would go to a machine shop and doing what a mechanical engineer would possibly be doing or dealing with as far as milling and stuff like that and I have to go speak that language. And then I would go home this summer and I would go work on my dirt bike and I would have to speak mechanical-ese with my dad. I don't know, you kind of get what I'm poking at there I guess? People say that they are this by nature but I don't really have a strong sense of that in any one area I guess.

So Brandon recognizes himself as having broad interests, and likely a range of identities. Thus, he seems comfortable with multiple identities, and doesn't see that as diminishing his identity with engineering.

Sara was a junior civil engineering student attending a medium-sized technically-focused institution. She identified only a single attitude as one of the top five for both engineers and herself (engineers: consideration of others, thoroughness, integrity, judgment, curiosity; self: consideration of others, respect, persistence, empathy and commitment). During the interview, she elaborated on this:

I: So you have [only] one [attitude] that crosses over between you and the engineers in general. What do you think about that?

Sara: I think that I am a little bit more caring, than you would assume an engineer would be.

I: I'd say so, by these words here. Have you seen that manifest itself somewhere, where these words are coming from? 
Sara: In talking to other people, I know how my decision will affect not just me, but it will also affect others than my peer engineers do. Kind of that notion.

I: So are these in conversations or classes or your co-op?

Sara: Classes, case studies, and things like that.

I: And this, what is the class called again professional?

Sara: Professional practice.

I: Professional practice, is that part of it?

Sara: Yeah, that has definitely influenced it. People or at least other peers have seemed a lot more cold than I do about things.

I: What you mean by cold?

Sara: Like, like...like we're talking about where to put, and we're talking about this in class, but where to put, we have to connect to areas of land and you have to decide who you're going to kick out of their homes. Are you going to kick out this many people because it costs less, or do you kick out less people but it costs more? More people choose the one where it costs less because it would be better for the company than the one that costs more because it doesn't displace as many people.

This section of the interview shows that Sara feels that she is somewhat different than her peers in the extent to which she cares about people. This seems supported by the fact that she selected more "people oriented" than "quality work" attitudes for herself.

Jolene selected three of the same attitudes for engineers and herself, but was still asked to reflect on differences.

I: Okay, so, let's see, thoroughness and curiosity are two in engineering that you don't have in yours and then empathy and respect are two that you have in yours, but not in engineering. So I'm wondering if you have any thoughts around this, just kind of what you think about that and that mismatch a little bit. I think you probably consider yourself an engineer or certainly getting there.

Jolene: I certainly want to be. I think the reason I didn't choose thoroughness for myself is, that's not I'd say one of my top five necessarily, qualities. I do, like thoroughness is going to come once you know the trade better. And you know how to be thorough about some things because right now if I am doing a take-off for some calcs that I have never looked at before then, I don't necessarily know how to be thorough because I don't know all the different components to look for, in a way. And so I think, and then some of the other things describe me more like being a thorough person. I do know you value respect and personally, I value respect more than necessarily thoroughness. So that's why those two. And then curiosity, I do wonder why and how those work, but I think it's part of engineering because that's kind of what pushes you to keep learning things and keep wondering about things in order to improve them. But I guess it's not one of my top five that. I would say I'm curious, but I am more, I value integrity more than I would be curious about it. So that my top five are more what I value personally than what I believe as an engineer.

I: But if you were to give 10 there would probably be more overlap?

Jolene: Yeah, I'm sure. I think all of these go along with what you need to be in order to be a really decent person and a good engineer. 
The interviews with the juniors indicated that these students seemed comfortable with any perceived differences in the attitudes of engineers and themselves personally. They seemed able to negotiate multiple identities, as needed. However, it is unclear if this same comfort is true for first year students, many of whom are developing their sense of what engineering is about and what it might mean to be an engineer.

\section{Summary and Conclusions}

The extent to which the students selected various attitudes from among a list of 18 as representative of engineers varied significantly, with some attitudes very common $(62 \%)$ and others very rare $(4 \%)$. There was less consensus on the attitudes that students identified as personally representative; all attitudes ranged from $52 \%$ to $11 \%$. There were six attitudes believed to represent engineers by $42 \%$ or more of the students: thoroughness, commitment, curiosity, high expectations, persistence, and integrity; four of these were also among the most prevalent personally ( $35 \%$ or more) - curiosity, commitment, high expectations, and persistence. The other three most common personal attitudes were consideration of others, respect, and positivity. Two of these three are reflective of people-centric attitudes. The least common attitudes selected for engineers (by 10\% or fewer students) were: tolerance, fairness, empathy, and sensitivity; these are all related to person-centric attitudes. The only two attitudes selected as personally representative by $11 \%$ or fewer students were judgement and sensitivity. The primary limitation of the current study is that the vast majority of the students $(\sim 90 \%)$ were all attending a single institution. The culture of that institution may differentially attract students with particular attitudes, as well as cultivate particular attitudes in students. In addition, the majority of the students were majoring in civil, environmental, or architectural engineering, so the results should not be considered generalizable to other engineering disciplines. Future work should be expanded to students at additional institutions and engineering disciplines.

Is it a problem that the attitudes that students most commonly associated with engineers tended to be those associated with producing quality work? Certainly this can be considered a positive. However, it is the exclusion of people-centric attitudes that is troubling. Many of the interviews with the junior students indicated that the students did not believe that these people-focused attitudes did not apply to engineers, but rather they felt that nearly all of the attitudes were applicable but were forced to select only five by the question. This idea could be explored more fully in the future, via research that allowed students to use a Likert-scale to rate each attitude, ranging from never associated with engineers to nearly always associated with engineers or perhaps a scale from should be characteristic of all engineers to not necessary for all engineers.

A limitation of the current work is the small number of upper-class students who participated in the study. Group 2 was a small group of civil engineering seniors; Group 3 was a small group of juniors from a variety of institutions and disciplines. Students from a wider range of engineering disciplines and institutions should be explored, and longitudinal studies would also be revealing. These extensions might reveal changes and/or differences that result from enculturation in different contexts. For example, programs that thread service-learning through a number of required courses in the curriculum (such as the SPLICE program at the University of Massachusetts Lowell) might result in graduates with different attitudes than a more traditional program. 
Further work should be expanded to explore issues associated with perceived attitudes for engineers, and whether this contributes to some students not selecting to major in engineering and/or leaving engineering majors. An easy extension of the current study might be to ask students majoring in architecture and environmental studies about attitudes that they believe are characteristic of those who work in those disciplines, as well as personally. As these are closely related to two of the engineering majors in this study, that might provide an interesting contrast. Further, students who leave engineering could be asked about their opinions, and perhaps ask to comment on personal attitudes that they feel are more characteristic of their new major as compared to their former engineering major. These same ideas could also be explored with individuals who are employed as engineers, individuals who graduated with degrees in engineering but work in non-engineering jobs, and those who have left engineering employment. Exploration of some additional attitudes not among those in this study could also be revealing, such as creativity, or expanding the list to include the full twenty attitudes from the BOK as well as additional attitudes.

I do believe that it is important to discuss expectations for professional attitudes with students, to raise their awareness that their success as engineers will depend on more than just their technical abilities. Perhaps seeing a broad list of attitudes will allow them to realize that engineering requires more than only the stereotypical "hard work", and there is a place for care and peoplecentric individuals. Presenting the BOK and discussing attitudes with students in the first year may help the students keep these attitudes in mind as they move through the curriculum, and they can be more aware of where these attitudes are being modeled in their courses and cocurricular activities even if they are not explicitly discussed. Faculty can be encouraged to discuss these attitudes with students in a syllabus (such as when they articulate grading criteria that require thoroughness or perhaps discussing the logic behind assumptions to demonstrate judgement). Discussion of the attitudes integrity and honesty would fit well into discussions of ethics and professionalism. More people-centric attitudes would be particularly appropriate to design courses.

\section{Acknowledgments}

Some of this material is based on work supported by the National Science Foundation under Grant \#1158863. Any opinions, findings, and conclusions or recommendations expressed in this material are those of the author(s) and do not necessarily reflect the views of the National Science Foundation.

\section{References}

1. Allen, J., R. van der Velden, editors. 2007. The Flexible Professional in the Knowledge Society: General Results of the REFLEX Project. Research Centre for Education and the Labour Market, Maastricht University, The Netherlands. http://cordis.europa.eu/docs/publications/1248/124857011-6_en.pdf Accessed Nov. 7, 2015.

2. ASCE (American Society of Civil Engineers). 2008. Civil Engineering Body of Knowledge for the $21 \mathrm{st}$ Century. Preparing the Civil Engineer for the Future. Second Edition. ASCE. Reston, VA.

3. Besterfield-Sacre, M., C.J. Atman, L.J. Shuman. 1997. Characteristics of freshman engineering students: models for determining student attrition in engineering. Journal of Engineering Education, 86 (2), $139-149$.

4. Cech, E.A. 2014. Culture of Disengagement in Engineering Education? Science, Technology \& Human Values. 39 (1), 42-72. 
5. Cone Inc. 2006. - The Millennial Generation: Pro-Social and Empowered to Change the World.ll The 2006 Cone Millennial Cause Study.

$<$ http://www.solsustainability.org/documents/toolkit/2006\%20Cone\%20Millennial\%20Cause\%20Study.pdf $>$.

6. Crawley, E.F., 2001. The CDIO Syllabus: A Statement of Goals for Undergraduate Engineering Education. MIT. http://www.cdio.org/files/CDIO_Syllabus_Report.pdf Accessed Nov. 25, 2015.

7. DeYoung, C.G., L.C. Quilty, J.B. Peterson. 2007. Between facets and domains: 10 aspects of the Big Five. Journal of Personality and Scoial Psychology, 93 (5), 880-896.

8. European Ministers of Education. 1999. The Bologna Declaration of 19 June 1999. http://www.magnacharta.org/resources/files/BOLOGNA DECLARATION.pdf Accessed Nov. 7, 2015.

9. Federation of European Accountants. 2009. Integrity in Professional Ethics: A Discussion Paper. Brussels. http://www.iia.nl/SiteFiles/Downloads/04januariIntegrity\%20in\%20Professional\%20Ethics\%20A\%20Discussio n\%20Paper\%200909\%20Colour.pdf Accessed Nov. 25, 2015.

10. Frye, A.L. 1962. The importance of attitude in young engineers. Chemical Engineering Education, Sept., p. 1923.

11. Gnambs, T. 2015. What makes a computer wiz? Linking personality traits and programming aptitude. Journal of Research in Personality. Oct. DOI: 10.1016/j.jrp.2015.07.004

12. Goldberg, D.E., M. Somerville. 2014. A Whole New Engineer: The Coming Revolution in Engineering Education. ThreeJoy Associates, Inc.

13. Gonzalez, J., R. Wagenaar, Eds. 2003. Tuning educational structures in Europe. Final Report. Phase 1. Universidad de Deusto.

14. Goshen, C.E. 1954. The Engineer Personality. The Bent of Tau Beta Pi. Dec. p. $15-16$.

15. Hall, C.W., P.J. Kauffmann, K.L. Wuensch, W.E. Swart, K.A. DeUrguidi, O.H. Griffin, C.S. Duncan. 2015. Aptitude and personality traits in retention of engineering students. Journal of Engineering Education, 104 (2), 167-188.

16. Hess, J.L., J.E. Sprowl, R. Pan, M. Dyehouse, C.A. Wachter Morris, J. Strobel. 2012. Empathy and caing as conceptualized inside and outside of engineering: extensive literature review and faculty focus group analyses. American Society for Engineering Education Annual Conference \& Exposition Proceedings. Paper AC20124456. $34 \mathrm{pp}$.

17. Hussain, S., M. Abbas, K. Shahzad, S.A. Bukhari. 2012. Personality and career choices. African Journal of Business Management, 6 (6), 2255-2260.

18. International Journal for Service Learning in Engineering, Humanitarian Engineering and Social Entrepreneurship. 2014. Special Issue: University Engineering Programs That Impact Communities: Critical Analyses and Reflection. 9 (SI), 1-562. 32 papers.

19. Litchfield, K. and A. Javernick-Will. 2014. Exploring EWB-USA Members' Descriptions of Self, Engineers, and their Fellow Members. International Journal for Service Learning in Engineering, 9 (1), 24-39.

20. Louie, M.C. 2004. Work in progress: Ethics and the development of professional identities of engineering students. $34^{\text {th }}$ ASEE/IEEE Frontiers in Education Conference, Oct. 20-23, Savannah, GA, pgs. T2E-11 - T2E12.

21. Lynch, D.R., J.S. Russell, J.C. Evans, K.G. Sutterer. 2009. Beyond the cognitive: The affective domain, values, and the achievement of the vision. Journal of Professional Issues in Engineering Education and Practice. 135 (1), 47-56.

22. Masnick, A.M., S.S. Valenti, B.D. Cox, C.J. Osman. 2010. A multidimensional scaling analysis of students' attitudes about science careers. International Journal of Science Education. 32 (5), 653-667.

23. McCuen, R. H., E.Z. Ezzell, M.K. Wong. 2011 Fundamentals of Civil Engineering: An Introduction to the ASCE Body of Knowledge. CRC Press. Boca Raton FL.

24. Millenbah, K.F., B.H.K. Wolter. 2009. The changing face of natural resources students, education, and the profession. Journal of Wildlife Management, 73 (4), 573-579.

25. National Academy of Engineering. 2004. The Engineer of 2020: Visions on Engineering in the New Century. National Academies Press. Washington DC.

26. National Academy of Engineering. 2008. Changing the conversation: messages for improving public understanding of engineering. Naitonal Academies Press. Washington DC.

27. Newport, C.L, D.G. Elms. 1997. Effective Engineers. Int. J. Engng. Ed. 13 (5), 325-332.

28. Ngambeki, I., M.M. Habashi, D. Evangelou, W.G. Graziano, D. Sakka, F. Corapci. 2012. Using profiles of person-thing orientation to examine the underrepresentation of women in engineering in three cultural contexts. International Journal of Engineering Education, 28 (3), 621-632. 
29. Nguyen, D.Q. 1998. The essential skills and attributes of an engineer: a comparative study of academics, industry personnel and engineering students. Global J. of Engng. Educ., 2(1), 65-76.

30. Ostroff, C. 1992. The relationship between satisfaction, attitudes, and performance: An organizational-level analysis. Journal of Applied Psychology, 77, 963-974.

31. Pertegal-Felices, M.L., J.L. Castejon-Costa, A. Jimeno-Morenilla. 2010. Personal and emotional skill profiles in the professional development of the computer engineer. Int. J. Engng. Ed. 26 (1), 218-226.

32. Pierrakos, O., T.K. Beam, J. Constantz, A. Johri, R. Anderson. 2009. On the development of a professional identity: engineering persisters vs. engineering switchers. $39^{\text {th }}$ ASEE/IEEE Frontiers in Education Conference, Oct. 18-21, San Antonio TX, M4F-1 to M4F-6.

33. Pooley, Erin (2005). —Kids These Days.ll Canadian Business. 78 (12).

34. Rulifson, G.A., A. Bielefeldt, W. Thomas. 2014. Understanding of Social Responsibility by First Year Engineering Students: Ethical Foundations and Courses. American Society for Engineering Education (ASEE) Annual Conference and Exposition Proceedings. June 15-18. Indianapolis, IN. Paper ID \#9425. 27 pp.

35. Strobel, J., J. Hess, R. Pan, C.A. Wachter Morris. 2013. Empathy and care within engineering: qualitative perspectives from engineering faculty and practicing engineers. Engineering Studies. 5 (2), 137-159.

36. Tawil, S., M. Cougoureux. 2013. Revisiting Learning: The Treasure Within. Assessing the Influence of the 1996 Delors Report. http://unesdoc.unesco.org/images/0022/002200/220050e.pdf Accessed Nov. 7, 2015.

37. Thompson, C. 2015. An insatiable curiosity make good engineers says Philadelphia CTO. CBS Philly. April 6, 2015. http://philadelphia.cbslocal.com/2015/04/06/an-insatiable-curiosity-make-good-engineers-saysphiladelphia-cto/ Accessed Nov. 6, 2015.

38. Turner, R., R. Opengart. 2008. Valuable systems engineering traits and behaviors at NASA's Marshall Space Flight Center. A study in support of the systems engineering leadership development program, Office of the Chief Engineer, NASA Headquarters. 20 pp. http://www.nasa.gov/pdf/291037main_10.5.5 APPENDIX_MARSHALL.pdf Accessed Nov. 24, 2015.

39. UNESCO. 1996. Learning: The Treasure Within. http://unesdoc.unesco.org/images/0010/001095/109590eo.pdf Accessed Nov. 7, 2015.

40. Van der Molen, H.T., H.G Schmidt, G. Kruisman. 2007. Personality characteristics of engineers. European journal of Engineering Educaiton, 32 (5), 494-501.

41. Vesilind, P.A. and Gunn A.S. (1998). Engineering, Ethics, and the Environment. Chapter 2. Engineering as a People-Serving Profession. Cambridge University Press, Cambridge UK.

42. Walesch, S.G. 2011. Creativity Plus Persistence Equals Breakthroughs. Leadership and Management in Engineering, 11 (2), 222.

43. Walesch, S.G. 2012. Engineering Your Future: The Professional Practice of Engineering. Third Edition. John Wiley \& Sons, Hoboken, NJ.

44. Walesch, S.G. 2012b. I don't care how much you know until I know how much you care. Leadership and Management in Engineering. 12 (2), 89-90. 